\title{
SECTOR TEXTIL COLOMBIANO Y SU INFLUENCIA EN LA ECONOMÍA DEL PAÍS
}

\author{
Paula Andrea Espinel González \\ Diana Marcela Aparicio Soto \\ Angela Julieta Mora
}

\section{Resumen}

En el presente trabajo se realiza un análisis acerca del sector textil colombiano, mediante el cual se logra presentar su influencia en la economía del país y la evolución que este ha tenido a lo largo de más de nueve décadas. Este trabajo contiene además una recolección de datos y cifras correspondientes a la actividad de los últimos tres años en los diferentes ámbitos del sector textil. Se busca recalcar también que el país puede llegar a ser un gran competidor a nivel internacional, así como logró adquirir importancia nacional a lo largo de los años.

El análisis frente a cómo interviene el sector textil en la economía del país se realizó con base en la información obtenida mediante diversas fuentes tales como documentos y estudios, que daban a conocer más a fondo cómo el país ha tenido una gran demanda en este sector, situación que ha llevado a innovar en la producción debido a la gran competitividad que se da mundialmente, no obstante en el presente trabajo se quiere dar a conocer una visión general de las condiciones positivas que trae consigo la producción textil, tanto para las empresas como la sociedad.

\section{Palabras claves}

Manufactura, competencia, negocios, producto, análisis, textil, economía, industria, comercio.

\section{INTRODUCCIÓN}

El siguiente trabajo tiene como objetivo responder a la pregunta: Según la producción del sector textil colombiano, ¿cómo influye este en la economía del país? Para cumplir con ello es necesario abarcar diferentes temáticas. Se hará una contextualización acerca del sector manufacturero, siendo este uno de los más importantes del país. Colombia se ubica entre el $3^{\circ}$ y $4^{\circ}$ puesto de los países latinoamericanos en cuanto a la producción manufacturera (Propais, 2014).

Para brindar una contextualización aún más completa se hará un recorrido histórico por el sector textil en Colombia, demostrando así la evolución que ha tenido y la importancia de las empresas nacionales. Por otro lado, se explicarán algunos de los factores que influyeron en el desarrollo del sector tales como la modernización, la globalización, el aumento de la demanda y la influencia de la segunda Guerra Mundial. Se dará una breve explicación acerca del proceso de producción del sector textil, presentando cifras extraídas de estudios del DANE e Inexmoda dando muestra de las principales empresas productoras que se hay y las ventas que se realizan en el país.

Se especificarán cuáles son tanto los socios comerciales como los países competidores para la industria textil colombiana, demostrando que el sector presenta gran competitividad y demanda en otros países. Además, se nombrarán 
los principales productos exportados y de mayor demanda internacional. Por último, se hará un análisis del crecimiento económico en Colombia con respecto al sector textil.

\section{Para contextualizar}

La actividad manufacturera también conocida como el sector secundario de la economía se encarga de la transformación continua y en volumen de materias primas en productos. La producción de manufacturas es totalmente independiente de los fenómenos naturales, al contrario que las actividades agrícolas. Dentro del sector manufacturero, se puede encontrar la producción de alimentos, maquinaria, industria automotriz, papel, químicos, calzado, textiles, entre otros.

Colombia tiene grandes beneficios debido a su posición geográfica, ya que cuenta con variedad de climas y ecosistemas aptos para la diversidad de producción y dos costas, que le permiten tanto la comunicación con países de Asia, como mayor facilidad de transporte a la hora de exportar; esto permite que los productos mencionados tenga una gran demanda, por ejemplo en los alimentos hay un excelente enfoque en el procesamiento y conservación de frutas, con el objetivo de elaborar productos tales como mermeladas, compotas, helados y otros, permitiendo que el PIB tuviera una expansión cercana del 5,5\% durante el año 2013 (Financieros, 2014).

En cuanto al sector automotriz, Colombia es el cuarto productor de vehículos, supera además la venta de 330 mil unidades dentro del país y en aras de la exportación (México, Ecuador, Perú y Chile) ha crecido. No se queda atrás con la producción de motos, que tiene un crecimiento aproximado anual de 16\% (Procolombia, 2013).

Del sector de calzado y marroquinería, se espera que el país para el 2018 se convierta en el tercer productor de Latinoamérica, siguiendo a Brasil y México y para lograr esto se necesita fortalecer la industria. "El sector del cuero es uno de los más representativos de la industria colombiana. Tiene una participación del 0,27\% en el PIB nacional y del 2,17\% en el PIB manufacturero (...)" (Propais, 2014). Hay cierta preocupación debido a que están entrando al país zapatos a precio muy bajo (a menos de cinco dólares), lo que afecta la demanda de los productos nacionales.

Por otra parte, el sector textil, se caracteriza por transformar telas, fibras e hilos en productos tales como accesorios o prendas de vestir. "El sector representa el 7,5\% del PIB manufacturero y el 3\% del PIB nacional, constituye más del 5\% del total de exportaciones del país" (Procolombia, Procolombia, 2015). En 2014 Colombia fue el $3{ }^{\circ}$ país de la región latinoamericana (por encima de Chile y México) que presentó crecimiento en este sector, con un aumento de ventas internas del 10\%. Gracias a su ubicación geográfica el país tiene acceso a más de 1.400 millones de consumidores y también se ve favorecido por los TLC que se han establecido con Mercosur, Nafta, Estados Unidos, la Unión Europea, el Triángulo Norte, Canadá y otros.

\section{Antecedentes}

Para analizar el sector textil en Colombia durante los últimos años (2013-2015) es necesario revisar la historia de esta industria en el país. El sector textil en Colombia tiene una gran trayectoria debido a la gran demanda de mercado que presenta para los colombianos, por lo que se remonta hacia 1907, cuando empezó la creación de las primeras empresas de tejidos en el país, algunas son Fábrica de Hilados y Tejidos El Hato, Compañía de Tejidos de Bello, Fábrica de Tejidos Hernández y Compañía Colombiana de Tejidos (Coltejer). En los años 50's se empezaron a crear empresas para productos específicos como fue el caso de Leonisa (Sectorial, 2011).

Con la gran acogida que se les dio a las empresas textiles, Colombia se abrió a la internacionalización de este sector pues se creó en 1980 la institución Inexmoda, la cual está enfocada en que el mercado textil se conozca mundialmente; consigo aparece (1989) Colombiamoda y Colombiatex de las Américas que permitirían abrir las negociaciones y los intercambios comerciales (Sectorial, 2011). 
Algunos de los dueños de las empresas textiles se dedicaban (antes de conformar su propia compañía) a importar telas y venderlas, de esta manera ya tenían conocimientos previos acerca del mercado y tenían gran demanda del producto. De manera general también influyeron en el desarrollo de la industria: 1) El crecimiento de la población a comienzos del siglo XX y 2) el asentamiento de las personas en las ciudades, situación que llevo a mayor demanda de productos textiles por el nuevo estilo de vida de las ciudades y por los mejores salarios que se recibían. Por otro lado, Los países participes de la $2^{\circ}$ Guerra Mundial empezaron a generar un comercio proteccionista, que hizo que los países de América Latina se vieran obligados a aumentar su producción nacional tanto de productos como de materiales para producir (en todos los sectores). Las guerras generan comercio y aquellos países producían en ese momento solo armas e importaban desde países latinos, como Colombia, textiles para los ejércitos (Arcila, 2009).

\section{Análisis del sector}

\section{Producción}

Dependiendo de la materia prima, el tipo de tela y el método de fabricación varía el proceso de producción textil. Por ejemplo, se habla de aspectos como:

- Insumos, fibras e insumos primarios: se encuentran las celulósicas, proteicas, sintéticas y artificiales.

- Textil (hilatura y tejeduría) e insumos para la confección: se cuenta con hilatura fibra corta e hilatura de filamentos.

- Diseño textil, servicios especializados y de acabados: se habla de teñido y diseño.

- Por último, se tiene en cuenta la confección y manufactura de indumentaria.

La cadena productiva (cifras del año 2014) del sector textil colombiano representa el 10\% de la producción industrial del país y casi el 6\% del total de las exportaciones. Por otro lado, Medellín es una de las principales ciudades productoras de textiles y es la principal productora de índigo, colorante usado en la fabricación textil (Inexmoda, 2011).

Este sector cuenta con aproximadamente diez mil fábricas repartidas en siete ciudades de Colombia, en primer lugar, en Medellín y Bogotá, seguidas de Cali, Pereira, Manizales, Barranquilla e Ibagué. Por su parte las empresas pioneras del país (Coltejer y Fabricato tejicondor) son las productoras del 34\% del tejido nacional, trabajando con algodón y sus mezclas. En Bogotá se fabrican tejidos de punto, a partir de mezclas de algodón y fibras sintéticas. Las empresas pioneras tienen una participación importante en la exportación del sector (40\%) y las empresas capitalinas por su parte dirigen el $89 \%$ de su producción para suplir la demanda nacional que completa con productos importados (encolombia, 2012).

Los subsectores de esta industria son: a) preparación e hilaturas; tejedura de productos textiles; b) fabricación de tejidos y artículos de punto y prendas de vestir y c) fabricación de otros productos textiles. Teniendo esto claro, según la encuesta de la industria manufacturera del año 2014 "el valor de las ventas y la producción aumentó para los tres subsectores, destacándose la actividad de comercio al por menor de prendas vestir, la cual incrementó 7,7\%. Así mismo, esta actividad presentó el mejor nivel de valor agregado $(8,1 \%) "$ (Francisco Reyez Villamizar, 2015).

En el año 2015, se generó un crecimiento de 1,5\% en producción de hilatura, tejeduría y acabado de productos textiles y $0,9 \%$ en ventas (Dinero, 2016). La calidad de los productos colombianos cada vez es más reconocida y valorada, siendo esto un factor importante para diferenciarse de los demás países.

\section{Principales Socios Comerciales y Competencia}

Los principales socios comerciales de Colombia del sector textil son Estados Unidos, México, Ecuador y Perú. En 2015 se exportaron a Estados Unidos 243 millones de dólares, mientras que las importaciones fueron de 
213 millones, el TLC con este país ha facilitado el comercio entre ambos países (Agredo, 2015). Las demás importaciones de Colombia provienen de China, Estados Unidos, India, México y Perú. Este último es de los principales importadores de vestidos de baño, ropa interior femenina y cueros. Ecuador es una economía importante para el sector, pues 2014 cerró con una exportación de más de 150 millones de dólares.

Colombia no es el principal exportador de textiles de México, Perú y Chile, pero si tiene potencial y gran oportunidad con la Alianza del Pacífico debido a que el país está en capacidad de abastecer la demanda y las relaciones comerciales se han visto favorecidas en los últimos años. De acuerdo con estadísticas de Trade Map, Colombia es el proveedor de textiles número 13 de México, $10^{\circ}$ de Chile y $4^{\circ}$ de Perú, después de China, EE. UU e India (Procolombia, 2014).

Procolombia explica que "en Chile, por ejemplo, la fabricación local es casi inexistente pero las marcas chilenas son fuertes y existe una alta influencia europea y argentina. No obstante, los diseñadores colombianos son reconocidos por sus prendas de alto valor agregado" (Procolombia, 2014) y tienen posibilidades al ofrecer ropa interior tanto femenina como masculina, calzado de cuero, marroquinería con alto diseño y vestidos de baño. Los principales competidores de Colombia son China, EE. UU, India, Perú, Pakistán, Brasil, Argentina, Corea del Sur y Vietnam. Para comerciar con México y Perú, Procolombia ha identificado como productos potenciales: calzado, manufacturas de cuero, ropa informal y deportiva, formal masculina, infantil e interior, textiles e insumos y vestidos de baño. Teniendo en cuenta datos del Dane, México ocupa el $4^{\circ}$ lugar de destino de exportaciones textiles colombianas y Perú el $5^{\circ}$. La competencia para Colombia en este caso son una vez más Estados Unidos, China, India, Corea del Sur, Vietnam y Bangladesh, Italia, Canadá, España, Alemania, Brasil, Argentina, Guatemala y Honduras (Procolombia, 2014).

\section{Crecimiento Económico en Colombia Frente al Sector Textil}

El sector textil en la economía de Colombia ha tenido una gran alza debido a que se está dando paso a las exportaciones, según informes del DANE en noviembre del año 2015 el sector presentó un crecimiento de 4,8\% en producción, $4,3 \%$ en ventas y $0,7 \%$ en generación de empleo, lo que muestra que la demanda que está teniendo en el mercado no solamente es nacional sino también internacionalmente, permitiendo generar un aumento en la economía. El sector textil en el país brinda más de 200 mil empleos directos y el triple de empleos indirectos. El $24 \%$ del empleo en el sector manufacturero lo genera esta industria (Inexmoda, 2011).

Para que la economía colombiana tenga una gran alza por medio del sector textil, se debe aprovechar la gran demanda de denim, ya que es una de las nuevas tendencias de consumo en los colombianos y mundialmente; de igual manera durante los últimos tres años, los vestidos de baño y la ropa interior trajeron más capital al país. El objetivo según César Maldonado, presidente de Protela, es darle un enfoque especial a estas prendas que están tomando auge en el mercado juvenil (Dinero, 2016).

El sector textil es uno de los más importantes en Colombia por tal motivo, para que exista mayor capital en el país se debe lograr el desarrollo y estabilidad del sector. "Es por este motivo que existen importantes retos para el sector, como el desarrollo de nuevos procesos logísticos, reducción de los costos de producción, mejorar la innovación tecnológica entre otras condiciones para llevar al exterior productos competitivos." Colombia está en capacidad de hacer esto. "Es por ello, que la mayoría de los tratados firmados por Colombia con otros países, contienen preferencias arancelarias que permiten ventajas para la entrada de textiles a otros países." (Tavera, 2014).

Para dar respuesta a la pregunta planteada al comienzo del presente trabajo, frente al predominio económico del sector textil en Colombia, queda claro que, durante estos tres últimos años, el PIB del país ha tenido una gran influencia por parte de este, ya que representa el 7,4\%. Claro está que al ser uno de los sectores que generan mayor economía en el país, en contraparte es uno en los que más predomina el contrabando por lo que se trabaja para contrarrestarlo. El país debe seguir trabajando también en controlar los productos que ingresan por ejemplo desde China, estos llegan con un precio muy bajo y pueden generar desequilibrios en el mercado nacional. Claramente los colombianos están en todo 
su derecho de preferir productos de otro continente y/o más económicos, pero lo ideal es que sea la economía nacional la que incremente en cifras cada año.

Colombia es un país con un alto potencial en el comercio global, aunque por supuesto se enfrenta a retos y obstáculos (al igual que todos los países). Uno de los propósitos que Colombia debería tener muy claros es invertir en investigaciones e innovar tanto maquinaria como productos, para poder ser diferenciados en el mercado internacional. Aunque se debe resaltar que la calidad de los productos colombianos siempre ha sido reconocida, situación cien por ciento favorable para el país. Por otra parte, tampoco se pueden perder de vista los constantes cambios de la demanda de los mercados, se debe estar en condiciones para poder adaptarse y responder ante las persistentes variaciones. Además, es muy importante mantener un equilibrio entre los factores costo, tiempo de producción y costo de ventas.

En Colombia la demanda en este sector es muy amplia, por lo cual no solamente se presenta dentro del país sino internacionalmente, por tal motivo con los diferentes tratados de libre comercio, el sector textil ha podido llegar a otras regiones permitiendo que se generen más exportaciones y consigo mayor productividad, negocios y hasta empleos, mejorando así la economía de los colombianos. Es necesario dar uso a los acuerdos comerciales que se han establecido a lo largo de la historia y que actualmente están vigentes, pues estos son una gran oportunidad para que Colombia continúe el proceso de internacionalización de su mercado.

Aunque la competencia del sector textil colombiano es por parte de grandes industrias tales como China, Estados Unidos, Corea del Sur, entre otros, como se ha mencionado anteriormente, el sector tiene potencial para seguirse desarrollando y mejorando cada vez más. De un año a otro no se puede sobrepasar a una de las potencias en el sector textil a nivel mundial; sumado a esto, Colombia no es el principal país destacado de América Latina, pues, Chile, Argentina e incluso Perú le llevan la delantera al país en varios aspectos, pero esto no significa que Colombia no pueda equilibrarse con ellos (al menos a nivel económico), el país no está en la pobreza total, hay materia prima, se pueden importar materiales estrictamente necesarios, hay producción, hay interés y hay factores a favor como la ubicación geográfica y otros.

Gracias a los Acuerdos de Libre Comercio que tiene Colombia con otros países, se ha visto también mayor crecimiento de la economía. Por supuesto, hay unos tratados que han favorecido más al país que otros; existen algunos en los cuales hay mayor confianza como la Alianza del Pacífico. Existe uno en especial que es el acuerdo comercial con Canadá, vigente hace menos de cinco años el cual ha representado bastantes avances para Colombia. Se busca que entre los dos países haya un mayor crecimiento económico, que permita el desarrollo tanto de Colombia como de Canadá, por tal motivo para generar ese progreso se está dando un enfoque importante al sector textil, debido a la gran demanda que se ha tenido, logrando así que sea uno de los sectores en los que más se destaque respecto a las exportaciones que se quieren generar a Canadá; debido a la gran variedad y buena calidad de las telas.

El Acuerdo de Promoción Comercial entre la República de Colombia y Canadá entró en vigencia el 15 de agosto de 2011. Su objetivo era crear un espacio libre de restricciones buscando un crecimiento y desarrollo económico mutuo. El acuerdo incluye la liberalización del comercio de bienes y servicios, tránsito de personas por negocios y turismo; inversiones, cooperación en el ámbito ambiental y laboral. Un objetivo más específico por parte de Colombia es incrementar las exportaciones del sector textil. Con el TLC, los exportadores de Colombia obtienen beneficios en muchos aspectos, tales como: eliminación de aranceles y generación en ambos países de contrataciones e inversiones.

El propósito del TLC consiste en fortalecer los lazos de cooperación entre las dos naciones, contribuir con el desarrollo armónico y de esta manera generar la expansión tanto mundial como regional y crear un mercado más extenso y seguro para los bienes y servicios producidos en sus territorios. Una de las fortalezas exportadoras colombianas es, precisamente, la cadena textil-confección, cuyos productos, como prendas de vestir y para el hogar, tienen acceso preferencial (no pago de aranceles) al mercado canadiense. 


\section{Productos y Aranceles}

Proexport y el Ministerio de Comercio, Industria y Turismo han señalado que los productos del sector textil con mayor oportunidad en Canadá son: hilado entorchado, fibras sintéticas, prendas de vestir (con valor agregado), suéteres, cardiganes e insumos para prendas de vestir; pijamas, ropa de hogar, encajes; trajes para hombre, ropa interior y fajas, vestidos de baño, artículos y ropa de dotación, manufacturas de cuero; bolsos de mano, accesorios, guata, tela sin tejer; hilados especiales, artículos de cordelería, sombreros; ropa deportiva y uniformes (inexmoda, 2010).

Existen cuatro categorías de acceso al mercado y desgravación arancelaria por parte de Canadá, estas son: inmediata, hasta 3 años, 7 años y 10 años. La mayoría de productos del sector textil-confección se encuentran en la categoría A (Acceso inmediato) y el arancel pasó de un $20-18 \%$ a $0 \%$; otros productos se encuentran en la categoría C (hasta 7 años). Los productos que todavía tienen arancel, es de un porcentaje entre 5 y 20.

\section{Canales de Distribución}

Teniendo en cuenta que un canal de distribución es un circuito escogido por los fabricantes/productores para llevar el producto al consumidor de manera eficiente y eficaz; el canal de distribución más usado para prendas de vestir entre Colombia y Canadá es:

$$
\text { Exportador/Productor } \rightarrow \text { Agente aduanero } \rightarrow \text { Importador/Agente } \rightarrow \text { Mayorista } \rightarrow \text { Minorista }
$$

Generalmente hay un distribuidor que trabaja desde Toronto o Montreal y cubre la región oriental de Canadá (Ontario, Quebec y Canadá del Atlántico) y otro en Calgary o Vancouver cubre Canadá Occidental. Dentro de la cadena de distribución se puede encontrar empresas para pedidos por correo, cadenas de tiendas y tiendas por departamentos; compradores directos al exportador y agentes locales. Una ventaja es que los agentes tienen conocimiento del mercado canadiense y ya están ubicados en el mercado, hacen el papel de intermediarios y pueden estar dispuestos a colaborar con los productores para que cumplan los requerimientos de cantidad, tamaño, empaque, etc.; y facilitan herramientas para poder entrar en el mercado canadiense.

Canadá tiene más de 200 puertos y subpuertos. Las mercancías de Colombia llegan principalmente a Halifax (Nueva Escocia), Montreal (Quebec), Toronto (Ontario) y el puerto de Vancouver (Columbia Británica) desde Buenaventura y Cartagena. En cuanto al acceso aéreo, las mercancías llegan a Pearson International (Toronto), Vancouver y Montreal, casi siempre con conexiones en Estados Unidos, Panamá o Cuba.

\section{Condiciones}

Para productos cuya materia prima viene de cuero de cocodrilos u otros reptiles considerados especies en peligro se debe demostrar que los animales de los cuales se obtuvieron las pieles crecieron en criaderos destinados para estos propósitos (inexmoda, 2010).

En el Acuerdo de Libre Comercio se encuentran medidas sanitarias, trato nacional y acceso al mercado, medidas de salvaguardia; política de competencia, especificaciones con respecto al medio ambiente; y comercio electrónico donde se manifiesta que las partes deben tener claridad y transparencia, innovación y competencia para facilitar este tipo de comercio, las partes deben proteger la información personal en línea, las pymes deben poder tener acceso al comercio electrónico; y debe haber una cooperación en este ámbito. Un aspecto que deben cumplir si o si los exportadores colombianos son las normas de medio ambiente, un ejemplo muy claro son los empaques biodegradables.

Dentro de las reglas de origen del acuerdo se encuentra: 
- La mercancía debe ser producida/obtenida totalmente en territorio de uno o ambos países, con materiales originarios. Los materiales no originarios no pueden sobrepasar el 55\% del valor de transacción de la mercancía.

- Una mercancía no será considerada originaria si: se realiza empaque o re-empaque para la venta al por menor de la mercancía; se aplica aceite, pintura anticorrosiva o recubrimientos protectores a la mercancía; hay desensamblaje de una mercancía nueva en sus partes (SICE, Reglas de Origen, 2013).

- Prueba de valor y valor de materiales.

- Regla de Minimis y Escaso abasto (SICE, Reglas de Origen, 2013).

- Además, existen unas reglas de origen específicos presentados en una lista.

Respecto al empaque, se puede decir que este protege los productos, evita el desperdicio, informa y salvaguarda a los consumidores y contribuye a que el negocio funcione. En el caso específico de Canadá, los paquetes deben ser fabricados y llenados de forma que no confunda al consumidor acerca de la calidad y/o cantidad del producto; todo debe tener etiquetas en inglés y francés que contengan el nombre y número de estilo del producto, color, peso de la caja en kilogramos, número de productos por contenedor, dimensiones de la caja, país de origen y nombre del exportador. El empaque actúa como un vendedor silencioso del producto a través de su diseño gráfico. Por tal motivo los empaques se pueden clasificar en tres grupos: empaque primario o de venta, empaque secundario o colectivo y empaque terciario o embalaje.

Respecto a los textiles y prendas de vestir como tal, se debe tener en cuenta el tipo de protección que necesitan, ya que pueden llegar a tener riesgos por: la humedad (moho), insectos (polillas), polvo, suciedad, luz (decoloración) y combustión. Por ello, la mejor manera de empacarlos y que sufran el menor daño posible, son en empaque de papel, por ejemplo bolsas, ya que los protegen de la luz y el polvo; al igual que el papel absorbe la humedad del aire y tienen a favor el ser económicos y de fácil eliminación. No obstante, otra forma de transportarlos es en el empaque de cartón corrugado, pues son los más utilizados para el transporte y protección de productos en exportaciones; además que se caracteriza por ser económico, reciclable y fácil de manipular.

En cuanto a las etiquetas de los productos, generalmente el comprador canadiense debe proporcionar las etiquetas para que el productor las costure en el producto. Ningún producto textil debe ser importado con etiqueta incompleta o incorrecta. Cuando el etiquetado sea terminado en Canadá, un inspector de Industria de este país debe ser notificado previamente acerca de los detalles de: naturaleza y cantidad de la importación, fecha y lugar de ingreso y la dirección donde se completará el etiquetado de los productos. La Fiscalía de la Nación tiene listas de los nombres genéricos aceptados para fibras naturales y artificiales. La ley canadiense exige que dentro del etiquetado se encuentre:

- $\quad$ El contenido de fibra con su nombre genérico, el porcentaje y composición por peso en inglés y francés (inexmoda, 2010).

- Quién fabrica el producto, quién lo importa y etiqueta (inexmoda, 2010).

- País de origen del artículo.

- Etiqueta con denominaciones mundiales del cuidado de las prendas (inexmoda, 2010).

Para exportar, los documentos necesarios son:

- DEX (Declaración de Exportación) y Certificado de origen.

- Factura proforma y factura comercial.

- Para envíos con valor menor a \$1.600 CAD (Dólar Canadiense), se requieren tres (3) facturas comerciales (Proexport, 2011).

- Para envíos con valor mayor o igual a \$1.600 CAD (Dólar Canadiense), se requieren tres (3) facturas expedidas por la Aduana de Canadá completamente diligenciadas y firmadas por la misma (Proexport, 2011). 
Si la factura expedida por la Aduana Canadiense no es correctamente diligenciada, se requerirá un depósito de seguridad.

- $\quad$ Lista de empaque y registros sanitarios o vistos buenos.

- Reporte de revisión y Certificado de inspección.

- Documento de transporte: Conocimiento de Embarque B/L (Bill of Lading), Carta de porte Aéreo AWB (Air Waybill), Conocimiento de Embarque Multimodal FBL y Certificado de Seguro de Transporte.

- Licencia para importar de la Oficina de Control de Exportación e Importación del Ministerio de Asuntos Exteriores y Comercio Internacional de Canadá.

Además de cumplir con los requisitos de la normativa canadiense, los exportadores pueden realizar certificaciones voluntarias adicionales que pueden incrementar la confianza del consumidor en su producto (TFO Canada, 2012). Cuando los canadienses buscan productos, el 33\% se fija en certificados que demuestren que los productos son responsables con el medio ambiente y socialmente. Dentro de los certificados aprobados que aplican para el sector textil están Fair Trade, The Standards Council of Canada, EcoLogo program y The CSA Group.

El Gobierno Federal canadiense impone una tasa del 6\% de valor agregado, que es el impuesto a los bienes y servicios (GST) vendidos a Canadá. Todos los importadores deben pagar el impuesto al valor agregado cuando los bienes entran a Canadá.

Fuente: (Procolombia, Exportando productos al Canadá, 2011).

\section{Oportunidades de Negocio}

"El gobierno canadiense es el principal comprador de ropa especializada para aerolíneas y de dotación de ropa hospitalaria, por lo que los exportadores colombianos pueden participar en los procesos de compras estatales como proveedores de empresas canadienses". Aquí se tiene una excelente oportunidad para el sector textil colombiano pues este subsector en Canadá presenta para Colombia un panorama bastante favorable (inexmoda, 2010).

Los productores que se concentran en los compradores jóvenes deben tener en cuenta que la ropa para equipos deportivos con telas que ofrezcan tratamientos anti-microbianos y anti-olor, regulación de la temperatura, protección UV y administración de la humedad, son una excelente oportunidad (inexmoda, 2010). Por otro lado, el estudio American Express Canada sobre los hábitos de compra de este país ha señalado que la generación "Y" (nacidos después de 1983) representa gran influencia en el mercado de ropa de lujo colombiana (NIG, 2000).

En el mercado canadiense existe una amplia gama de competencia por lo que los exportadores si quieren generar realmente negocio deben ofrecer productos innovadores o con alto valor agregado ya sea en términos de diseño, calidad, precio, servicio postventa y otros. Por otra parte, Canadá tiene una cultura que se preocupa e interesa bastante por el medio ambiente, la salud y el ahorro de tiempo, por ende, estos tres aspectos son claves para poder generar negocios en este país; si se ofrecen productos amigables con el ambiente y la salud de seguro el exportador tendrá más oportunidades. Además, los canadienses están interesados en productos duraderos y de calidad; y estos son dos elementos que caracterizan a la producción colombiana.

También se debe tener en cuenta a los baby boomers, pues esta parte de la población generalmente tiene mayor poder adquisitivo que las demás. Una excelente idea de negocio es pensar en telas ecológicas y con sello de Fair Trade. También los empaques son atractivos para los negociantes de Canadá, por esto son un elemento importante a tener en cuenta para poder ser competitivos en el mercado.

\section{Opciones de Empresa}


En este acuerdo se han establecido medidas acerca de la Cooperación relacionada al Comercio que favorece a las pymes, uno de los objetivos de esta cooperación es "promover el desarrollo económico sostenible, con énfasis en las pequeñas y medianas empresas, a fin de contribuir a la reducción de la pobreza a través del comercio" (SICE, Cooperación relacionada al Comercio, 2013). Otro objetivo es promover oportunidades para el comercio y la inversión, estimulando la competitividad e impulsando la innovación.

Actualmente ya hay 1.156 empresas exportadoras colombianas ubicadas principalmente en Bogotá-Cundinamarca (426), Antioquia (417) y Valle del Cauca (107). Aunque ya hay varias empresas exportadoras, aún hay posibilidades y oportunidades para nuevas empresas. Ya que Canadá es un importante productor del sector textil, las empresas colombianas se encontrarán con mayor competitividad en el país, pero esto en vez de acorralar a los exportadores colombianos, debe ser un incentivo para ser innovadores y posicionar las marcas colombianas.

En resumidas cuentas, los canadienses prefieren calidad, productos y empaques amigables con el ambiente; gran parte de la población tiene alto poder adquisitivo por lo que los precios no son un problema siempre y cuando el producto sea llamativo. Las dos generaciones que más activas son en el comercio son los mayores y los jóvenes. Con lo anteriormente planteado, se da a conocer las oportunidades tan grandes que hay al exportar productos del sector textil a Canadá, sabiendo que Colombia se caracteriza por su alta calidad en telas, haciéndolas llamativas para los consumidores de ese país; que buscan productos que sean de agrado para los canadienses y muy importante, que puedan generar el crecimiento en la economía.

Colombia cuenta con todas las reglamentaciones requeridas para exportar productos tales como: vestidos de baño, sudaderas, ropa deportiva, ropa interior, jeans, etc. Los documentos, el empaque y el embalaje al igual que el etiquetado, entre otros, son puntos importantes para que el comprador se sienta seguro de la negociación que va a llevar a cabo con Colombia; debido a que los productos textiles pueden llegar a sufrir daños durante la exportación, el vendedor se encarga de que todas esas inconsistencias puedan manejarse de la mejor manera y de esta forma lograr su llegada satisfactoriamente.

Por otro lado, no solo los canadienses gozan de productos de calidad, al mejor precio y con el mejor diseño colombiano, sino que también el mercado de Colombia se está viendo favorecido por este TLC en el sector textil. Los resultados de los casi seis años que tiene de vigencia el Acuerdo demuestran que uno de los sectores que más se ha desarrollado y más exportaciones ha tenido es el sector textil. Se debe aceptar que Canadá también es fuerte en el sector textil y por ello es competencia directa para Colombia, pero dejando a un lado esto, Canadá es un país que representa para Colombia oportunidades de expansión; los productores colombianos pueden ser más competitivos al aprovechar las oportunidades que el Acuerdo les brinda y además Canadá es un país que tiene relaciones comerciales con países mucho más grandes y desarrollados económicamente hablando, y esto puede favorecer de una u otra manera al comercio colombiano.

\section{Bibliografía}

Agredo, P. (28 de Julio de 2015). Minuto 30. Obtenido de minuto 30: http://www.minuto30.com/estados-unidosprimer-socio-comercial-de-colombia-en-el-sector-textil/368328/

Arcila, J. C. (2009). LA INNOVACIÓN COMO DETERMINANTE DE COMPETITIVIDAD EN LA INDUSTRIA TEXTIL-CONFECCIÓN: EL CASO DE COREA Y COLOMBIA. Trabajo de grado, Bogotá. Recuperado el 11 de Abril de 2016, de http://javeriana.edu.co/biblos/tesis/economia/tesis56.pdf

Camilo Herrera, S. R. (2009). Confexiones y Textiles: aún hay destinos inexplorados .

Colombia, P. (2003). Cartilla Empaques y Embalajes para Exportación. Bogotá. 
Colombia, P. (s.f.). Proexport Colombia. Obtenido de Proexport Colombia: http://es.slideshare.net/pasante/3oportunidades-comerciales-en-canad

(2015). Colombia: Balance 2014 y perspectivas 2015. Bogotá.

Comercio y Aduanas. (s.f.). Comercio y Aduanas. Obtenido de Comercio y Aduanas: http://www.comercioyaduanas.com.mx/comercioexterior/comercioexterioryaduanas/375-documentacionde-transporte-para-el-comercio-internacional

Dinero. (02 de Abril de 2016). Obtenido de Dinero: http://www.dinero.com/edicionimpresa/negocios/articulo/resultados-del-sector-textil-en-el-ano-2016-en-colombia/218787

EFE. (28 de Julio de 2015). el Nuevo Herald. Obtenido de el Nuevo Herald: http://www.elnuevoherald.com/noticias/mundo/america-latina/colombia-es/article29130139.html

encolombia. (s.f.). Obtenido de encolombia: https://encolombia.com/economia/infoeconomica/algodon/industriatextil/

Financieros, A. S. (2014). El procesamiento y conservación de frutas en Colombia. Medellín.

Francisco Reyez Villamizar, J. A. (2015). Desempeño del sector textil-confección 2012-2014. Bogotá.

Inexmoda. (s.f.). Obtenido Inexmoda: https://www.inexmoda.org.co/Laferia/Datosdeutilidad/tabid/180/language/en-US/Default.aspx inexmoda. (2010). Manual de Acceso a Mercados del Sector Textil-Confección Diseño y Moda Colombiano .

Latinpyme. (23 de Enero de 2015). Obtenido de Latinpyme: http://latinpymes.com/articulo/3267

Leonardo Ángel López, J. E. (21 de Marzo de 2013). Perfil del sector manufacturero Colombiano. Cali. Obtenido de http://datateca.unad.edu.co/contenidos/102504/Contenido_curso/2014-

II_Contenidos/lectura_adicional_5._Sector_manufacturero_colombiano.pdf

Modelo Factura. (s.f.). Obtenido de Modelo Factura: http://www.modelofactura.net/factura-pro-forma.html

NIG, F. (s.f.). Fenalco. Obtenido de Fenalco: http://www.fenalcoatlantico.com.co/2012-03-08-05-54-14/interessectorial/88-textiles-la-oportunidad-de-colombia-en-canada-con-el-tlc

Procolombia. (s.f.). Obtenido de Procolombia: http://inviertaencolombia.com.co/sectores/manufacturas/textil-yconfeccion.html

$\begin{array}{llll}\text { Procolombia. } & \text { (s.f.). Obtenido } & \text { Procolombia: }\end{array}$ http://inviertaencolombia.com.co/sectores/manufacturas/automotriz.html

Procolombia. (s.f.). Obtenido de Procolombia: http://www.procolombia.co/

Procolombia. (Enero de 2014). Obtenido de Procolombia: http://www.procolombia.co/noticias/sector-colombianotextil-confecciones-tiene-oportunidades-con-la-alianza-del-pac\%C3\%ADfico

Procolombia. (2015). Procolombia. Obtenido de Procolombia: http://inviertaencolombia.com.co/sectores/manufacturas/textil-y-confeccion.html

Procolombia. (s.f.). Exportando productos al Canadá.

Proexport. (2011). Perfil de Logística desde Colombia hacia Canadá.

Propais. (2014). Sector de cueros en Colombia.

Sectorial. (13 de 12 de 2011). Obtenido de Sectorial: https://www.sectorial.co/articulos-especiales/item/50352

SICE. (s.f.). Cooperación relacionada al Comercio.

SICE. (s.f.). Reglas de Origen.

Tavera, A. G. (2014). El sector textil enColombia, ¿cómo ser más competitivos? Especialización en Gerencia en Comercio Internacional, Universidad Milotar Nueva Granada, Bogotá.

TFO Canada. (s.f.). Obtenido de TFO Canada: http://www.tfocanada.ca/docs.php?page=2_8

Todocarga. (s.f.). Todocarga. Obtenido de Todocarga: http://todocarga.com/exportacion/declaracion-de-exportacion/ 